\title{
Influencia de variables estacionales, espaciales, biológicas y ambientales en la bioacumulación de mercurio total y metilmercurio en Tagelus dombeii
}

\author{
Influence of seasonal variables, location and biological and environmental factors on the \\ bioaccumulation of total mercury and methilmercury in Tagelus dombeii \\ Oscar Díaz ${ }^{1}$, Francisco Encina ${ }^{2}$, Lizandro Chuecas ${ }^{3}$, José Becerra ${ }^{3}$, José Cabello ${ }^{3}$ \\ Angélica Figueroa ${ }^{4}$ y Franz Muñoz ${ }^{1}$ \\ ${ }^{1}$ Facultad de Química y Biología, Universidad de Santiago de Chile. Casilla 40, Correo 33. Santiago Chile. \\ ${ }^{2}$ Facultad de Ciencias, Universidad Católica de Temuco. Dirección Postal 15-D. Temuco. Chile. \\ ${ }^{3}$ Facultad de Ciencias Naturales y Oceanográficas. Universidad de Concepción. Casilla Postal 2407. Concepción. Chile. \\ ${ }^{4}$ Centro EULA Chile. Universidad de Concepción. Casilla 156-C Concepción Chile. \\ odiaz@lauca.usach.cl
}

\begin{abstract}
Resumen.- Se realizó un estudio en la bahía San Vicente (Concepción, Chile) tendiente a establecer la influencia de variables estacionales, espaciales, biológicas y ambientales en la capacidad de bioacumulación de $\mathrm{Hg}$ total y $\mathrm{CH}_{3} \mathrm{Hg}$ en el hepatopáncreas y el músculo pedal de Tagelus dombeii. Los resultados obtenidos permitieron establecer que en la época de invierno, se produce la mayor bioacumulación tanto de $\mathrm{Hg}$ total como de $\mathrm{CH}_{3} \mathrm{Hg}$, época en la cual el hepatopáncreas tiende a acumular una concentración de $\mathrm{Hg}$ total, equivalente al doble del nivel medido en el músculo pedal. Desde un punto de vista espacial, el lugar de muestreo es determinante en la capacidad de bioacumulación de $\mathrm{Hg}$ total y $\mathrm{CH}_{3} \mathrm{Hg}$ en ambos tejidos. En cuanto a las variables biológicas, el sexo y la edad mostraron la mayor influencia en la capacidad de $T$. dombeii para bioacumular $\mathrm{Hg}$ total y $\mathrm{CH}_{3} \mathrm{Hg}$ en el hepatopáncreas. Los machos acumulan aproximadamente un $50 \%$ más $\mathrm{Hg}$ total que las hembras, y a medida que los organismos aumentan en edad, la capacidad de bioacumular también aumenta. Los altos niveles de $\mathrm{Hg}$ total medidos en el material particulado, el sedimento y las fuentes antrópicas, permiten deducir una clara influencia del ambiente en la capacidad de bioacumulación tanto de Hg total como de $\mathrm{CH}_{3} \mathrm{Hg}$ en los tejidos de los individuos. Debido a la capacidad de bioacumular y por constituir una población genéticamente homogénea, $T$. dombeii representa una especie adecuada para su uso como monitor biológico en estudios ambientales marino costeros.
\end{abstract}

Palabras claves: Bioacumulación, Mercurio total, Metilmercurio, Bioindicador, Tagelus dombeii, bahía San Vicente.

\begin{abstract}
A study was undertaken in the Bay of San Vicente (Concepción, Chile ) to investigate the influence of seasonal variables, location and biological and environmental factors on the bioaccumulation of $\mathrm{CH}_{3} \mathrm{Hg}$ and total $\mathrm{Hg}$ in liver and foot muscle of Tagelus dombeii. The results obtained demonstrate that the bioaccumulation of both $\mathrm{CH}_{3} \mathrm{Hg}$ and total $\mathrm{Hg}$ are most pronounced in winter, with an average accumulation of total $\mathrm{Hg}$ in the liver double that of the foot muscle. The location of the sample determines the extent of accumulation of both $\mathrm{CH}_{3} \mathrm{Hg}$ and total $\mathrm{Hg}$ in both tissues. The sex and age of $T$. dombeii are the most important biological variables in the determination of bioaccumulation of $\mathrm{CH}_{3} \mathrm{Hg}$ and total $\mathrm{Hg}$ in the liver. Males accumulate approximately $50 \%$ more total $\mathrm{Hg}$ than females and accumulation increases with age. High levels of total $\mathrm{Hg}$ were detected in suspended particulate matter, sediments and anthropological sources and demonstrate the clear influence of the environment on the bioaccumulation of both $\mathrm{CH}_{3} \mathrm{Hg}$ and total $\mathrm{Hg}$ in the tissues of individuals. Given the ability to bioaccumulate and the fact that the population is genetically homogeneous, make $T$. dombeii an excellent choice for monitoring mercury accumulation in marine environments.
\end{abstract}

Keyword: Bioaccumulation, Total Mercury, Methylmercury, Bioindicator, Tagelus dombeii, San Vicente Bay.

\section{Introducción}

Los estudios sobre contaminación marina son de gran importancia en ambientes estuarinos y costeros, donde las descargas tanto de residuos industriales como domésticos son altas.
La bioacumulación consiste en la capacidad de los organismos de acumular selectivamente contaminantes en sus tejidos respecto de las concentraciones existentes en el medio en que habitan (The Royal Society, 1979; Riisgard et al. 1985; International Programme on Chemical Safety, IPCS, 1989). 
Debido al potencial de organismos marinos, especialmente algas e invertebrados que concentran metales traza, se ha sugerido su uso como organismos de vigilancia o monitoreo en ambientes estuarinos y costeros, ya que permiten integrar espacial y temporalmente las variaciones ambientales de estos metales (Lobban et al, 1985, White \& Rainbow 1987, Sharp et al. 1988, Díaz, et al. 1993).

Borchardt et al. (1988), establecieron que una serie de variables juegan un rol significativo en el proceso de acumulación de un elemento traza en un individuo y en estudios relacionados con organismos monitores de contaminación. Tales variables lo constituyen la naturaleza biológica (talla, sexo, posición del organismo en la cadena trófica, relaciones genéticas entre poblaciones etc.) y ambientales (calidad del agua, calidad y cantidad de alimento y otros). Estos autores, en un trabajo tendiente a medir la concentración de elementos traza, entre ellos mercurio, en Mytilus edulis recolectado en regiones estuarinas y costeras, establecieron que el nivel del elemento está influenciado por parámetros tales como; el período de muestreo, la talla de los organismos y su condición corporal.

Estudios realizados en variadas especies de organismos marinos, concluyen que la concentración de mercurio aumenta en la misma proporción en que aumenta la edad del individuo y varia según el sexo. En algunas especies de machos se han encontrado niveles de mercurio superiores a los medidos en hembras (IPCS 1989). Kayrallah (1985), estudió el efecto tanto del cloruro de mercurio como del metilmercurio en el anfípodo Bathyporeia pilosa, estableciendo que la toxicidad estaba directamente relacionada con la concentración del compuesto y con la edad de los organismos. Minganti et al. (1990), en un trabajo realizado en Nephrops norvegicus recolectado en el mar de Liguria, encontraron diferencias significativas en las concentraciones de mercurio total y orgánico en ambos sexos, hecho que fue atribuido a diferencias en la edad. Por otra parte, Hight (1987) y Hight \& Corcoran (1987), establecieron que los moluscos bivalvos son entre los organismos marinos, el grupo más recomendado para su uso como organismos monitores de contaminación acuática. Estos organismos juegan un rol esencial en los estudios relacionados con la evaluación de la calidad del ambiente marino (The Royal Society 1979, Riisgard et al. 1985 and Phillips 1990).

La bahía San Vicente ( $36^{\circ} 44^{\prime}$ S; $73^{\circ} 09^{\prime}$ O), se caracteriza por ser un área altamente industrializada con un importante complejo industrial en los rubros acero, petroquímicos, desembarque y procesamiento de pescado (Ahumada et al. 1989).

Los principales contaminantes de la bahía San Vicente son desechos orgánicos derivados de la industria pesquera y efluentes urbanos, así como también metales pesados derivados de la industria química y metalmecánica, especialmente del efluente de la Planta de cloro-soda, Occidental Chemical Chile. S.A.I (Salamanca et al. 1988, Ahumada, op. cit. 1989, Chuecas 1989, Ahumada 1994).

Los principales metales que superan las concentraciones en el agua de mar en la bahía San Vicente, con respecto tanto al estándar EPA (0.10 ppb) como también a la concentración natural promedio, sin especificar para que tipo de ambiente, corresponden a $\mathrm{Cd}, \mathrm{Pb}, \mathrm{Hg}, \mathrm{Mn}, \mathrm{Cu}, \mathrm{Zn}$ y Ag (Chuecas, 1989 y Ahumada, 1994). Los sedimentos varían la concentración de $\mathrm{Hg}$ entre un valor máximo de $265 \pm$ $184.4 \mu \mathrm{g} \mathrm{g}^{-1}$ (b.s) en el punto de vaciado del efluente de un complejo petroquímico en el Estero Lenga y $0.045 \pm$ $0.036 \mu \mathrm{g} \mathrm{g}^{-1}$ (b.s) en el punto más distante a la desembocadura de este estero (Hoffmann 1978).

Tagelus dombeii, molusco bivalvo filtrador de ambiente bentónico litoral de amplia distribución en el sur de Chile, habita en sectores con predominancia de arenas medianas, con alta proporción de arenas finas, formando bancos en playas con escaso movimiento. Su alimentación consiste fundamentalmente de material sólido suspendido en la columna de agua y detritus. Su distribución batimétrica es de 3 a 15 m (Montecinos 1986).

Con el fin de dimensionar el grado de acumulación de Hg total en algunos tejidos de Tagelus dombeii, se calculó el índice de bioacumulación del elemento a partir de las concentraciones promedio medidas en el agua de fondo. Este análisis junto al de todas aquellas variables que puedan afectar la acumulación de Hg total y $\mathrm{CH}_{3} \mathrm{Hg}$, facilitarán su uso como organismo monitor de tales contaminantes químicos en ambientes costeros.

\section{Materiales y Métodos}

\section{A) Materiales}

El material de análisis comprendió; organismos, agua de mar, sólidos suspendidos, sedimento y residuos industriales líquidos, los cuales fueron recolectados trimestralmente en cuatro estaciones de muestreo e igual número de campañas, llevadas a cabo entre Febrero de 1993 y Marzo de 1994.

\section{A.1) Material biológico}

El material biológico empleado en este estudio, correspondió a organismos pertenecientes a la especie Tagelus dombeii.

Un sector de la franja costera de la bahía San Vicente ( $36^{\circ} 44^{\prime}$ Lat. S; $73^{\circ} 9^{\prime}$ Long. W), fue seleccionado para fijar las estaciones de muestreo del 
material de análisis. La Fig. 1, muestra el área de estudio y la ubicación de las estaciones de muestreo.

De cada estación (E), se obtuvo un número no inferior a 10 organismos, mediante buceo autónomo y aplicando el método estadístico de muestreo al azar simple sin reemplazo. La extracción de los organismos se realizó utilizando un cuchillo de acero inoxidable y a una profundidad de $c a .6 \mathrm{~m}$.

El procedimiento de conservación y transporte del material biológico, se realizó de acuerdo con lo establecido por United Nations Environmental Programme, UNEP 1984, Castagna et al. 1985, Santoro \& Koepp 1986 y Minganti et al. 1990.

En el laboratorio, a cada organismo se le extrajo el hepatopáncreas y el músculo pedal, mediante instrumentos de disección de acero inoxidable. Estos tejidos fueron pesados separadamente en una balanza analítica (Sartorius, modelo A-200, precisión de 1x10-4 g.). Luego cada tejido fue rotulado para su identificación, estableciéndose claramente la procedencia de cada organismo, mantenidos a temperatura de congelación ($25^{\circ} \mathrm{C}$ ) hasta ulterior liofilización (liofilizador marca Vir Tis, modelo $\mathrm{N}^{\circ} 10$ - 146 MR BA) a - 50 C y $50 \mu \mathrm{g} \mathrm{Hg}$ de vacío.

Del material liofilizado, se obtuvo ca. $0.2 \mathrm{~g}$, el que fue macerado y homogeneizado mediante un mortero Agata (UNEP 1985).

Las variables biológicas analizadas fueron;

- Peso y Talla: Se midieron según los Métodos de Referencia para Estudios de Contaminación Marina (UNEP, 1984).

- Sexo: Se determinó mediante un examen microscópico del tejido gonadal de cada individuo (Villarroel \& Stuardo 1977).

- Edad: Se estableció mediante la lectura de las líneas de crecimiento en la valva de cada organismo (Defeo et. al. 1988).

- Relaciones genéticas entre poblaciones; Fueron analizadas poblaciones de $T$. dombeii obtenidas tanto de la zona costera de la bahía San Vicente, altamente contaminada por especies de mercurio y de la zona costera de Nercón (Chile X Región), con niveles bajos de mercurio. Entre ambos lugares existe una distancia de aproximadamente $500 \mathrm{Km}$. Se examinaron loci de cuatro enzimas usando el método de electroforesis gel-almidón de proteínas aplicado por Leary \& Booke (1989) y Mechan et al. (1989), como medio para detectar diferencias genéticas entre poblaciones.

\section{A.2) Agua de mar}

Se recolectaron muestras de agua de mar, con el fin de establecer en que medida el ambiente acuático de $T$. dombeii influencia en éste la acumulación de mercurio total y el impacto que pueda ejercer en el ambiente costero el aporte antrópico del elemento, representado tanto por el efluente de la Planta de cloro-soda Occidental Chemical Chile S.A.I., como por los residuos descargados en las aguas del Estero Lenga.

Las muestras de agua de mar se obtuvieron de la capa superficial (0.5 m de la superficie) y de fondo (1.5 $\mathrm{m}$ sobre el fondo). Para tal efecto, se utilizó una botella Nansen marca Hydro Bios de 1.5 L de capacidad y siguiendo el procedimiento recomendado por UNEP (1985) y Campbell et al. 1986. Se recolectó una muestra de cada estación E y A (Fig. l). Estas estaciones fueron ubicadas tomando como punto de referencia la posición del efluente industrial, de manera de establecer la influencia de la variable espacial en las concentraciones de mercurio total en el ambiente de $T$. dombeii, así como en su capacidad de bioacumulación.

\section{A.3) Sólidos suspendidos}

El material sólido suspendido se obtuvo con el fin de establecer la influencia que ejerce el alimento en el ingreso de mercurio a los organismos y por lo tanto en la capacidad de bioacumulación. El material se obtuvo mediante filtración a partir de un volumen no inferior de $500 \mathrm{ml}$ de agua de mar recolectada de las estaciones $\mathrm{E}$ y A. Para tal efecto, se utilizó filtro de membrana de nitrocelulosa $(0.45 \mu)$, aplicándose a continuación el procedimiento recomendado en los Métodos de Referencia para Estudios de Contaminación Marina (UNEP 1985).

\section{A.4) Sedimento}

Se obtuvo una muestra compuesta a partir de tres submuestras de la capa superior $(5 \mathrm{~cm})$ procedentes de cada estación E. Para tal efecto se utilizó un equipo Corer de material plástico de $c a .50 \mathrm{~cm}$ de longitud y $5 \mathrm{~cm}$ de diámetro.

El transporte y conservación de las muestras, se llevó a cabo según los Métodos de Referencia para Estudios de Contaminación Marina (UNEP 1985). En el laboratorio las muestras de sedimento fueron congeladas $\mathrm{a}-25^{\circ} \mathrm{C}$ y luego liofilizadas. Con el fin de homogeneizar el tamaño de las partículas, a las muestras de sedimento liofilizadas, se les practicó un análisis granulométrico utilizando un tamizador de $63 \mu \mathrm{m}$ (UNEP op. cit., Grosheva 1993). 


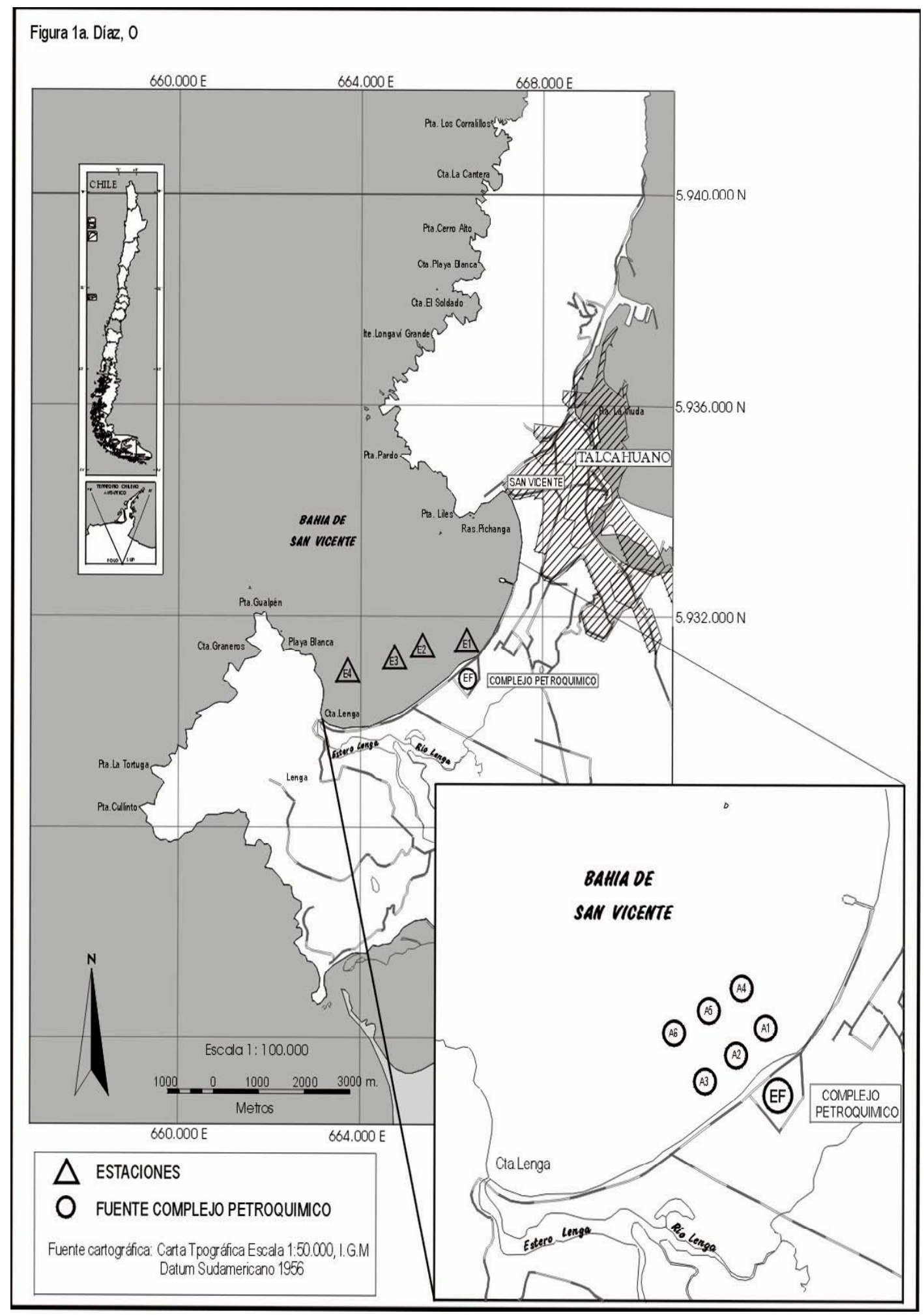

Figura 1

Área de estudio y estaciones de muestreo.

La figura muestra la ubicación geográfica de las estaciones de muestreo E, A y el Efluente Industrial (EF).

Study area and location of sampling stations.

$\mathrm{EF}=$ Industrial effluent. The figure shows the geographic position of the sampling station $\mathrm{E}, \mathrm{A}$ and the Industrial Effluent (EF). 


\section{A.5) Residuos industriales líquidos}

Se recolectaron dos muestras compuestas procedentes de dos puntos de la trayectoria del efluente de la Planta de cloro-soda, Occidental Chemical Chile. S.A.I , con el fin de establecer el impacto de tales residuos en el área de estudio. El primer punto, correspondió al lugar más próximo a las instalaciones de la Planta, mientras que el segundo punto es el sitio de descarga de los residuos líquidos en la zona costera (Fig. l).

Cada muestra fue almacenada en una botella de vidrio de $1 \mathrm{~L}$ de capacidad, debidamente identificada y transportada al laboratorio de acuerdo con el procedimiento establecido por UNEP op. cit.

\section{B) Métodos}

\section{B.1. Concentración de mercurio total}

El método analítico utilizado para medir la concentración de $\mathrm{Hg}$ total, fue espectrofotometría de absorción atómica por vapor frío (CVAAS), previa liofilización y digestión en ácido nítrico de las muestras sólidas (Campbell et al. 1986, Shaw et al. 1988, Colina \& Romero 1989, Dangwal 1993). En este sentido, se utilizó un sistema analizador de mercurio marca Bacharach modelo 50 B con bomba incorporada.

La precisión del método analítico se estimó calculando el coeficiente de variación porcentual (\%CV) de la concentración de mercurio total en submuestras. Si el valor obtenido es superior al $10 \%$, el procedimiento analítico puede tener errores debido a contaminación. En este caso todos los reactivos deberían ser revisados mediante análisis de blanco. (UNEP op. cit. Encina et al. 1995).

En este estudio el valor promedio del coeficiente de variación fue de $8.5 \%$, resultante del análisis de cuatro submuestras de agua de mar, cuya concentración media alcanzó a $0.76 \pm 0.065 \mu \mathrm{g} \mathrm{Hg} \mathrm{L}^{-1}$.

La exactitud del método CVAAS, se determinó midiendo la concentración de $\mathrm{Hg}$ total en tres submuestras de estándar certificado (Tort 1, Lobster liver), según el procedimiento recomendado por UNEP op. cit.; Encina et al. op. cit.

La concentración media obtenida en los análisis de las submuestras, fue de $0.34 \mu \mathrm{g} \mathrm{Hg} / \mathrm{g} \pm 0.01$, mientras que el valor declarado es de $0.33 \mu \mathrm{g} \mathrm{Hg} / \mathrm{g} \pm 0.06$, resultado que permite asegurar el cumplimiento de las condiciones de exactitud requeridas.

\section{B.2) Concentración de metilmercurio}

El método de análisis aplicado para medir la concentración de $\mathrm{CH}_{3} \mathrm{Hg}$, fue el de cromatografia gaseosa con detección por captura de electrones (GCECD), previa liofilización de las muestras sólidas (UNEP 1984, Hight 1987 y Horvat \& Byrne 1990).

Se usó un cromatógrafo gas-líquido marca Varian Aerograph modelo 2700, conectado a un integrador de registro marca Waters modelo 740. El equipo de GC se encontraba acoplado a un detector de captura de electrones $\left(\mathrm{Ni}^{63}\right)$ como fuente radioactiva.

La exactitud del método, se determinó midiendo la concentración de $\mathrm{CH}_{3} \mathrm{Hg}$ en tres submuestras de estándar certificado (Tort 1, Lobster liver) y aplicando el procedimiento recomendado por UNEP op. cit. La concentración media obtenida en los análisis de las submuestras, fue de $0.12 \mu \mathrm{g} \mathrm{CH} 3 \mathrm{Hg} / \mathrm{g} \pm 0.01$, mientras que el valor declarado es de $0.128 \mu \mathrm{g} \mathrm{CH}_{3} \mathrm{Hg} / \mathrm{g} \pm 0.014$, resultado que permite determinar que el método aplicado cumple con las condiciones de exactitud requeridas.

El material de laboratorio utilizado en todos los análisis, fue de vidrio Pyrex tratado pre y pos análisis según lo recomendado por UNEP op. cit. UNEP 1985 y Encina et al. 1995.

El factor de bioacumulación para Hg total, se calculó mediante la razón entre la concentración del elemento en el organismo y la existente en el agua de fondo, ambiente con el cual interactúan estrechamente los individuos (Ahumada 1994). Este cálculo se efectuó para cada estación y época de muestreo. Debido a que no se midió la concentración de $\mathrm{CH}_{3} \mathrm{Hg}$ en el agua de mar por tratarse de una molécula insoluble en este medio, no se calculó el factor de bioacumulación para esta forma orgánica.

\section{Resultados y Discusión}

\section{Concentración de $\mathrm{Hg}$ total y $\mathrm{CH}_{3} \mathrm{Hg}$ en tejidos de T. dombeii}

\subsection{Influencia de parámetros espaciales}

La Tabla 1, presenta las concentraciones promedio de $\mathrm{Hg}$ total y $\mathrm{CH}_{3} \mathrm{Hg}$ en hepatopáncreas (HP) y músculo pedal (MP), pertenecientes a los organismos colectados en cada estación de muestreo y durante todo el período de estudio.

De la Tabla 1, se puede observar que el hepatopáncreas extraído de los organismos recolectados en la estación E4, revelaron acumular la mayor concentración tanto de $\mathrm{Hg}$ total como de $\mathrm{CH}_{3} \mathrm{Hg}$, respecto del resto de las estaciones.

En cuanto al músculo pedal, se puede apreciar que las muestras pertenecientes a los organismos obtenidos 
Tabla 1

Concentración de $\mathrm{Hg}$ total y $\mathrm{CH}_{3} \mathrm{Hg}$ en tejidos de $\mathrm{T}$. dombeii, recolectado en cada estación de muestreo.

Concentration of total $\mathrm{Hg}$ and $\mathrm{CH}_{3} \mathrm{Hg}$ in tissues of $T$. dombeii, collected from each sampling station.

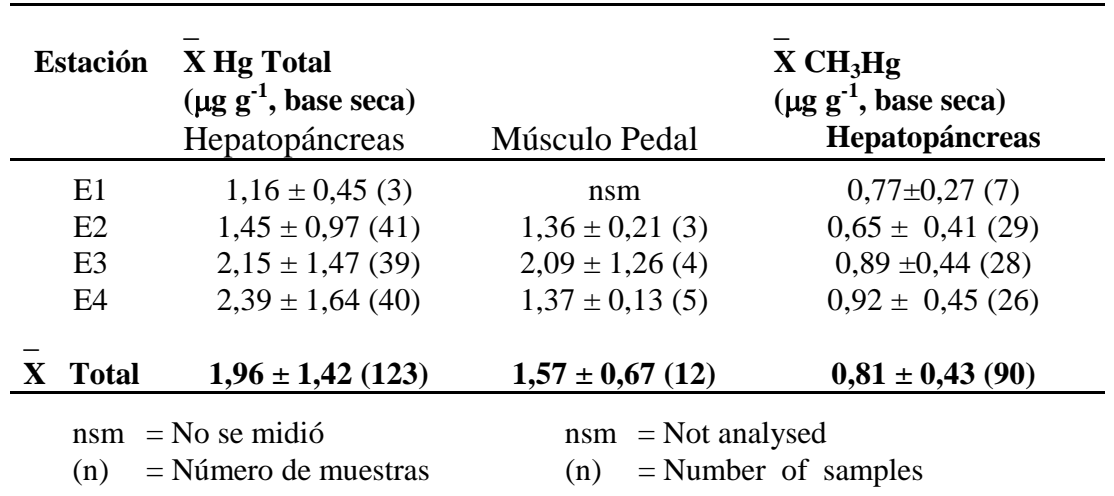

de la estación E3, manifestó acumular la mayor concentración de $\mathrm{Hg}$ total respecto del resto de las estaciones.

Estos resultados permiten atribuir una notable influencia del lugar de muestreo (variable espacial), en la capacidad de $\mathrm{T}$. dombeii de acumular $\mathrm{Hg}$ total y $\mathrm{CH}_{3} \mathrm{Hg}$, hecho que está relacionado con la posición de las fuentes que aportan el elemento al ambiente. Para establecer el nivel de significancia de las diferencias tanto de $\mathrm{Hg}$ total como de $\mathrm{CH}_{3} \mathrm{Hg}$, se procedió a realizar un análisis de medias de tipo no paramétrico (Kruskal Wallis), obteniéndose un valor $\mathrm{p}=0.01$ en ambos casos, lo que permite determinar que las diferencias son significativas.

Por otra parte, como se estableció precedentemente, durante años el Estero Lenga ha estado recibiendo aportes de $\mathrm{Hg}$ procedente de industrias petroquímicas que descargan sus efluentes a sus aguas. El Estero desemboca en la zona costera próxima a la ubicación de las estaciones E3 y E4 (Fig. l), cuyos organismos manifestaron contener las mayores concentraciones tanto de $\mathrm{Hg}$ total como de $\mathrm{CH}_{3} \mathrm{Hg}$ en ambos tejidos.

Este hecho ha sido determinado por numerosos autores, quienes concluyen que la mayor capacidad de los organismos de concentrar $\mathrm{Hg}$ total y sus formas químicas, está asociada con la proximidad a la (s) fuente(s) que abastecen el elemento al ambiente (Donazzolo et al. 1984, Borchardt et al. 1988, Riisgard \& Hansen 1990, Díaz 1993 y Díaz et al. 1995).

En el caso de este estudio, la situación descrita se ve favorecida por dos hechos:

i) El Estero Lenga vacía sus aguas y sedimentos a la zona costera de la bahía San Vicente, encontrándose en este punto los mayores niveles de Hg total en el agua, el cual alcanza una concentración de $0.8 \mu^{-1} L^{-1}$ (Hoffmann 1978).

Con respecto a la concentración de $\mathrm{Hg}$ total en el sedimento extraído del Estero Lenga, se midió la mayor concentración equivalente a $265 \pm$ $184.4 \mu \mathrm{g} \mathrm{g}^{-1}$ (base seca) en un punto donde descargan los desechos provenientes de un complejo petroquímico (Hoffmann 1978).

En este mismo estudio, se midió la concentración de $\mathrm{Hg}$ total en Aulacomya ater, Mytilus chilensis y Chorus chorus correspondiente a 1.5 $\mu \mathrm{g} \mathrm{g}^{-1}, 1.33 \mu \mathrm{g} \mathrm{g}^{-1}$ y $1.1 \mu \mathrm{g} \mathrm{g}^{-1}$ sobre base húmeda, respectivamente.

El sedimento fino $\mathrm{y}$ con alto contenido de materia orgánica, constituye las condiciones óptimas para que se acumule Hg en él, favoreciendo la biotransformación de este en $\mathrm{CH}_{3} \mathrm{Hg}$ por acción bacteriana, siendo incorporados por los organismos del agua como seria el caso de $T$. dombeii (Hoffmann, 1978; Salamanca et. al., 1988; Grosheva, 1993 y Díaz et. al., 1996).

ii) La corriente marina superficial dominante en bahía San Vicente, tiene sentido antihorario, es decir, se dirige de Sur a Norte (Ahumada et al., 1989). Respecto de la ubicación de las estaciones de muestreo, el transporte de Hg se dirigiría por lo tanto desde la estación E4 a El, explicándose de esta manera que la primera de las estaciones nombradas se encuentra más expuesta al elemento aportado por el Estero Lenga que por el efluente de la Planta de cloro-soda, ubicado a mayor distancia de la estación E4. En este caso, el Hg se transportaría desde la estación El (más próxima al efluente), hacia la localidad de Talcahuano (Fig. l).

Es de hacer notar que en esta estación, se observa una significativa disminución de individuos pertenecientes a la especie $T$. dombeii $(\mathrm{n}=3)$, respecto a E4 ( $n=40)$. La desfaunación observada es atribuible no solo a la influencia del efluente de la Planta de clorosoda, sino también a otros emisarios industriales y domésticos que vacían sus desechos a la zona costera en el sector comprendido entre la estación El y la ciudad de Talcahuano (Fig. l).

\subsection{Influencia de variables estacionales}

La Tabla 2, presenta las concentraciones medias de Hg total y $\mathrm{CH}_{3} \mathrm{Hg}$ en el hepatopáncreas y músculo pedal, según el periodo de muestreo. 
Tabla 2

Concentración de $\mathrm{Hg}$ total y $\mathrm{CH}_{3} \mathrm{Hg}$ en tejidos de $\mathrm{T}$. dombeii, según periodo de muestreo.

Concentration of total $\mathrm{Hg}$ and $\mathrm{CH}_{3} \mathrm{Hg}$ in tissues of $T$. dombeii whith respect to sampling periods.

\begin{tabular}{|c|c|c|c|}
\hline Campaña & $\begin{array}{l}\text { X Hg Total } \\
\text { ( } \mu \mathrm{g} \mathrm{g}^{-1} \text {, base seca) } \\
\text { Hepatopáncreas }\end{array}$ & Músculo Pedal & $\begin{array}{l}\overline{\mathrm{X}} \mathrm{CH}_{3} \mathrm{Hg} \\
\text { ( } \mu \mathrm{g} \mathrm{g}^{-1} \text {, base seca) } \\
\text { Hepatopáncreas }\end{array}$ \\
\hline C1 Verano & $0,71 \pm 0,28(30)$ & $1,18 \pm 0,35$ (3) & $0,45 \pm 0,90(25)$ \\
\hline C2 Otoño & $1,43 \pm 0,61(32)$ & nsm. & $0,71 \pm 0,28(24)$ \\
\hline C3 Invierno & $3,92 \pm 1,26(31)$ & $1,86 \pm 0,79(6)$ & $1,05 \pm 0,90(20)$ \\
\hline C4 Primavera & $1,78 \pm 0,59(30)$ & $1,23 \pm 0,70$ (3) & $1,15 \pm 0,35(21)$ \\
\hline
\end{tabular}

Tabla 3

Factores de bioacumulación para Hg total.

Bioaccumulation factor values of total $\mathrm{Hg}$.

\begin{tabular}{ccc}
\hline $\begin{array}{c}\text { Estación - } \\
\text { Campaña }\end{array}$ & \multicolumn{2}{c}{ Factor de Bioacumulación } \\
& Hepatopáncreas & Músculo Pedal \\
\hline E1 & 2367 & nsm \\
E2 & 3815 & 3578 \\
E3 & 5243 & 5097 \\
E4 & 6638 & 3050 \\
C1 & 572 & 952 \\
C2 & 7150 & $n s m$ \\
C3 & 6322 & 3000 \\
C4 & 1271 & 878 \\
\hline
\end{tabular}

$\begin{aligned} \mathrm{nsm} & =\text { No se } \\ \mathrm{nsm} & =\text { Not analysed. }\end{aligned}$

capacidad de bioacumulación de $\mathrm{Hg}$ total en ambos tejidos, a excepción del hepatopáncreas perteneciente a los organismos recolectados en la estación E4, en que se manifiesta una relación equivalente casi al doble respecto al músculo pedal de estos organismos.

El factor de bioacumulación más alto, se registró en los tejidos pertenecientes a los organismos recolectados en las estaciones E3 y E4. Este hecho se refuerza al observar la Tabla 2, la cual muestra una mayor concentración tanto de $\mathrm{Hg}$ total como de $\mathrm{CH}_{3} \mathrm{Hg}$ en el hepatopáncreas y músculo pedal correspondientes a los organismos colectados en las indicadas estaciones.

Estos resultados permiten confirmar la influencia espacial en la capacidad de bioacumulación del elemento.

Los valores obtenidos son superiores a los encontrados por Ahumada (1994), quien en un estudio tendiente a medir el índice de bioacumulación correspondiente a varios metales pesados, entre ellos el $\mathrm{Hg}$, en el cuerpo blando de variados invertebrados bentónicos recolectados en bahía San Vicente, entre los que se cuenta Tagelus dombeii, encontró valores que fluctúan entre los 361 y 723 en la mencionada especie, dependiendo del lugar de recolección.

A pesar de que ambos trabajos fueron realizados independientemente $\mathrm{y}$ en el mismo período, las diferencias encontradas pueden deberse al hecho de que en el estudio citado se consideró el cuerpo blando total, mientras que en este trabajo los tejidos analizados, particularmente el hepatopáncreas, corresponde a aquellos cuya capacidad para bioacumular metales pesados, tales como el Hg, es conocida (Santoro \& Koepp 1986, Riisgard \& Hansen, 1990). 
Con respecto a los valores del factor de bioacumulación en los tejidos de Tagelus dombeii, según el período de muestreo, se puede apreciar de la Tabla 4 que los mayores valores se registraron en los hepatopáncreas pertenecientes a los organismos recolectados en la época Otoño-Invierno, hecho que reafirma lo establecido precedentemente en cuanto a que la concentración mas alta de Hg total, se midió en los tejidos correspondientes a los individuos obtenidos en Invierno (Tabla 3), lo cual explicablemente se debe manifestar en un valor alto para el factor de bioacumulación.

\subsection{Influencia de parámetros biológicos}

\subsubsection{Peso y talla}

La Tabla 4, muestra los valores promedio de peso y talla de $T$. dombeii, obtenidos en cada período de muestreo y la relación entre estos parámetros con la concentración de $\mathrm{Hg}$ total y $\mathrm{CH}_{3} \mathrm{Hg}$ en el hepatopáncreas.

Esta Tabla complementa los resultados presentados en la Tabla 3.

De la Tabla 4, se puede apreciar la ausencia de relación directa entre el peso y la talla de los individuos, con su capacidad para bioacumular $\mathrm{Hg}$ total y $\mathrm{CH}_{3} \mathrm{Hg}$ en el hepatopáncreas. En efecto, la mayor o menor capacidad de concentrar el elemento y su forma metilada, es función del período en el cual se recolectaron los organismos (efecto estacional, Tabla 3), el cual influye en la biodisponibilidad del elemento. El análisis de correlación practicado a los valores promedios de peso y talla respecto a la concentración de $\mathrm{Hg}$ total y $\mathrm{CH}_{3} \mathrm{Hg}$ en el hepatopáncreas, resultó en valores negativos y con un alto nivel de significancia, ( $\mathrm{p}$ $=0.01$ y 0.03), respectivamente para las variables peso y talla, en el caso de $\mathrm{CH}_{3} \mathrm{Hg}$ y $\mathrm{Hg}$ total, resultado que ratifica la no existencia de relación directa entre los parámetros biológicos considerados y la concentración de estos agentes químicos.

\section{Tabla 4}

Valores promedio de peso (g) y talla $(\mathrm{mm})$ en $T$. dombeii y su relación con la concentración de $\mathrm{Hg}$ total y $\mathrm{CH}_{3} \mathrm{Hg}$ en el hepatopáncreas, según período de muestreo.

Average values of weight (g) and size (mm) in T. dombeii and its relation with the concentration of total $\mathrm{Hg}$ and $\mathrm{CH}_{3} \mathrm{Hg}$ in the liver, according to sampling periods.

\begin{tabular}{ccccc}
\hline Campaña & $\begin{array}{c}\text { Peso } \\
(\mathbf{g})\end{array}$ & $\begin{array}{c}\text { Talla } \\
(\mathbf{m m})\end{array}$ & \multicolumn{2}{c}{$\begin{array}{c}\text { Concentración } \\
\left(\boldsymbol{\mu} \mathbf{g ~ g}^{-\mathbf{1}} \text {, base seca) }\right.\end{array}$} \\
\hline & & & Hg Total & $\mathbf{C H}_{3} \mathbf{H g}$ \\
C1 & 39,81 & 90,80 & $0,71 \pm 0,28$ & $0,45 \pm 0,19$ \\
C2 & 36,52 & 71,27 & $1,43 \pm 0,61$ & $0,71 \pm 0,28$ \\
C3 & 35,50 & 70,93 & $3,92 \pm 1,26$ & $1,05 \pm 0,49$ \\
C4 & 38,19 & 72,34 & $1,78 \pm 0,59$ & $1,15 \pm 0,35$ \\
\hline
\end{tabular}

Estos resultados no concuerdan con los obtenidos por Minganti et al. (1989), quienes concluyeron que la concentración de $\mathrm{Hg}$ total en Nephrops norvegicus recolectado en el mar de Liguria, aumentaba exponencialmente con la talla del organismo.

Por otra parte, Riisgard y Hansen (1990), en un estudio experimental llevado a cabo en el bivalvo Mytilus edulis, tendiente a evaluar la capacidad de biomagnificación de $\mathrm{Hg}$ total y $\mathrm{CH}_{3} \mathrm{Hg}$ (i.e: acumulación progresiva del agente químico a lo largo de la cadena alimentaria), concluyeron que la tasa de acumulación parece ser dependiente de la talla; los organismos más pequeños tenían una tasa de incorporación de mercurio inorgánico más rápida que los organismos más grandes.

Capelli et al. (1990), analizaron la concentración de Hg total y $\mathrm{CH}_{3} \mathrm{Hg}$ en Adamussium colbecki, organismo bentónico recolectado en varios puntos de la bahía de Terra Nova (Antártica), estableciendo que no había suficiente correlación entre la concentración de tales agentes químicos y la talla de los organismos.

En un informe sobre niveles y distribución de metales pesados y pesticidas en agua, sedimentos marinos y organismos pertenecientes a la especie Aulacomya ater (cholga), recolectados entre la I y IV Región de Chile, se concluyó que existe relación entre el peso y la talla de los individuos y la concentración de Hg total. En efecto, los organismos de mayor peso y talla, evidenciaban una mayor concentración de Hg total y viceversa (Chuecas et al. 1988).

La talla por sí sola, puede no tener efecto en la bioacumulación de $\mathrm{Hg}$ total y $\mathrm{CH}_{3} \mathrm{Hg}$ en una determinada especie de organismo, como pudiera ser el caso de $T$. dombeii, pero sí pueden influir los efectos combinados del período de muestreo, la talla y la condición corporal, como lo estableció Borchardt et al. (1988), en un estudio llevado a cabo en Mytilus edulis.

Se requieren más estudios que puedan dilucidar si el peso y la talla juntos o separadamente, ejercen algún tipo de influencia en la bioacumulación de $\mathrm{Hg}$ y sus especies químicas en un determinado organismo, o si como lo estima Phillips (1980), tales variables son dependientes de la edad del individuo.

\subsubsection{Sexo}

Las Fig. 2 y 3, representan los resultados obtenidos respecto de la concentración de $\mathrm{Hg}$ total y $\mathrm{CH}_{3} \mathrm{Hg}$ en el hepatopáncreas de $T$. dombeii, diferenciado según el sexo.

De las Fig. 2 y 3, se puede observar la notable influencia del sexo en la bioacumulación tanto de $\mathrm{Hg}$ total como de $\mathrm{CH}_{3} \mathrm{Hg}$ en el hepatopáncreas de los organismos. Los machos tienden a acumular en mayor 


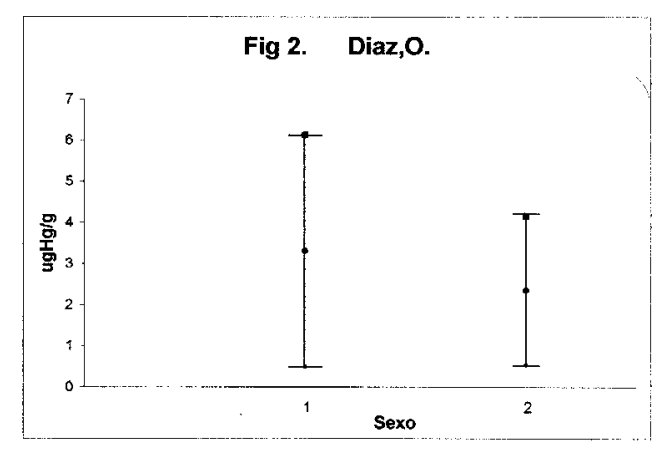

Figura 2

Concentración de Hg total según sexo.

La figura muestra que la concentración de Hg total es mayor en machos (1) que en hembras (2).

Concentration of total $\mathrm{Hg}$ according to sex. The figure shows that the total $\mathrm{Hg}$ concentration is most higher in male (1) than female (2).

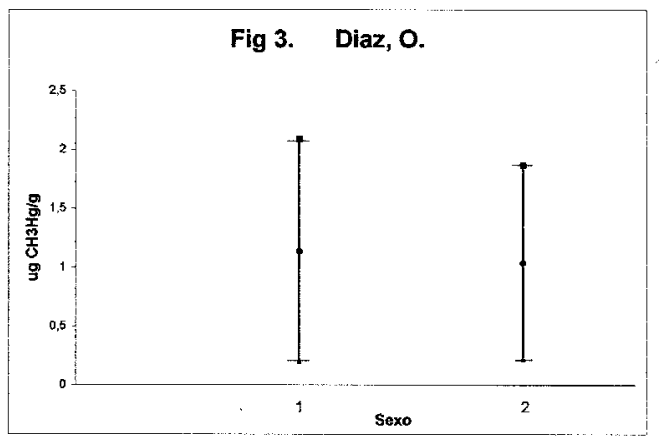

Figura 3

Concentración de $\mathrm{CH}_{3} \mathrm{Hg}$ según sexo.

La figura muestra que la concentración de $\mathrm{CH}_{3} \mathrm{Hg}$ es mayor en machos (1) que en hembras (2)

Concentration of $\mathrm{CH}_{3} \mathrm{Hg}$ according to sex.

The figure shows that the $\mathrm{CH}_{3} \mathrm{Hg}$ concentration is most higher in male (1) than female(2).

medida que las hembras a ambos agentes químicos, resultando ser esta diferencia altamente significativa $(\mathrm{p}<$ 0.01) en el caso de la concentración de Hg total, pero no así, en el caso de la concentración de $\mathrm{CH}_{3} \mathrm{Hg}$.

Estos resultados concuerdan con los hallazgos de Riisgârd \& Hansen (1990), quienes concluyeron que el sexo constituye un parámetro biológico decisivo para explicar las diferencias encontradas en la concentración de Hg orgánico e inorgánico en las especies Cardium edule y Mytilus edulis. Sin embargo, Capelli et al. (1990), concluyeron que no hay suficiente correlación entre la concentración de Hg total y orgánico respecto al sexo en la especie Adamussium colbecki.

Minganti et al. (1989), estiman que las variaciones en la concentración de Hg total en ambos sexos de la especie Nephrops norvegicus, se explica por diferencias en la edad.

\subsubsection{Edad}

Las Fig. 4 y 5, presentan los resultados relacionados con la concentración de $\mathrm{Hg}$ total y $\mathrm{CH}_{3} \mathrm{Hg}$ en el hepatopáncreas de $T$. dombeii, de acuerdo con la edad de los organismos, expresada en número de líneas de crecimiento.

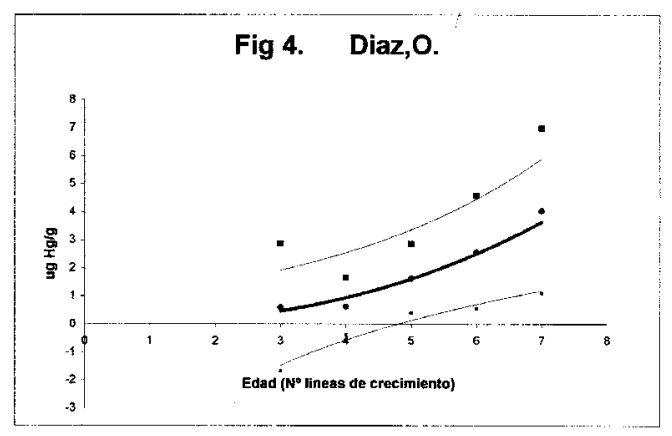

Figura 4

Concentración de Hg total según edad.

La figura muestra que la concentración de Hg total aumenta con la edad. Los números en el eje $x$ representan las líneas de crecimiento.

Concentration of total $\mathrm{Hg}$ according to age.

The figure shows that total Hg concentration increases according to age. The number in the $\mathrm{x}$-axis, represent the lines of growth.

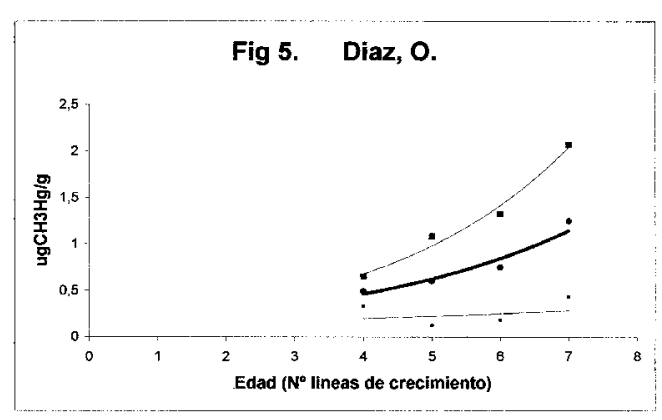

Figura 5

Concentración de $\mathrm{CH}_{3} \mathrm{Hg}$ según edad.

La figura muestra que la concentración de Hg total aumenta con la edad. Los números en el eje $x$ representan las líneas de crecimiento.

Concentration of total $\mathrm{CH}_{3} \mathrm{Hg}$ according to age.

The figure shows that total $\mathrm{CH}_{3} \mathrm{Hg}$ concentration increases according to age. The number in the $\mathrm{x}$-axis, represent the lines of growth. 
Vol. 36, No 1, 2001

De las Fig. 4 y 5, se puede apreciar la notable influencia de la edad en la bioacumulación de Hg total y $\mathrm{CH}_{3} \mathrm{Hg}$ en el hepatopáncreas de los organismos. En efecto, ambos agentes químicos tienden a acumularse progresivamente a medida que aumenta el número de líneas de crecimiento, las que según Defeo et al. (1989), corresponde a los individuos más adultos y viceversa, resultando ser estas diferencias altamente significativas $(\mathrm{p}<0.01)$.

Estos resultados se ven confirmados por los valores de correlación (r) obtenidos, los que para el caso de la relación entre acumulación de $\mathrm{Hg}$ total y $\mathrm{CH}_{3} \mathrm{Hg}$, según la edad de los individuos, alcanzó a $\mathrm{r}=0.84$ y r $=0.78$ respectivamente.

Estos resultados concuerdan con los hallazgos alcanzados por Riisgard \& Hansen (1990), quienes atribuyeron la alta concentración de mercurio orgánico medido en Cardium edule, a la edad de los organismos, hecho que para estos autores igualmente fue atribuido a individuos pertenecientes a la especie Mytilus edulis.

\subsubsection{Relaciones genéticas en dos pobla- ciones de T. dombeii}

Se consideraron las enzimas fosfoglucomutasa (Pgm-1), isocítrico deshidrogenasa (Idh - 1), leucina aminopeptidasa (Lap - 2) y glutamato oxaloacetato transferasa (Got - 1). Las frecuencias de alelos para cada locus y población, se muestran en la Tabla 5.

De la Tabla 5, es posible observar que las frecuencias de alelos en cada locus para ambas poblaciones, son similares. La mayor similitud entre el grupo de organismos recolectados en bahía San Vicente y aquellos obtenidos en Nercón, se presenta en las enzimas Idh - 1 y Lap - 2, cuyos alelos C y D no están presentes en la primera y el alelo $\mathrm{D}$ se encuentra solamente en la segunda. Los locus de las enzimas Pgm - 1 y Got - 1 del grupo de organismos obtenidos en Nercón, el alelo B está presente en una alta frecuencia.

Estos resultados permiten deducir que desde el punto de vista de las relaciones génicas, las dos poblaciones analizadas son similares, a pesar de haber sido recolectados en puntos muy distantes.

Mechan et al. (1989), llegaron a resultados similares al analizar las frecuencias de alelos en el loci de 11 enzimas de organismos pertenecientes a la especie Macoma balthica, un bivalvo que habita en fondos marinos y estuarinos. Las poblaciones de organismos fueron obtenidas de la bahía San Francisco, California, en la costa del Pacífico y en el río Potomac, Maryland, ubicada en la bahía de Chesapeake en la costa del Atlántico. En este estudio se encontró una alta similitud en las frecuencias alélicas de cada locus en las poblaciones analizadas.
Tabla 5

Frecuencia alélica en cada locus para dos poblaciones de T. dombeii

Allele frequencies at each locus for two populations of T. dombeii.

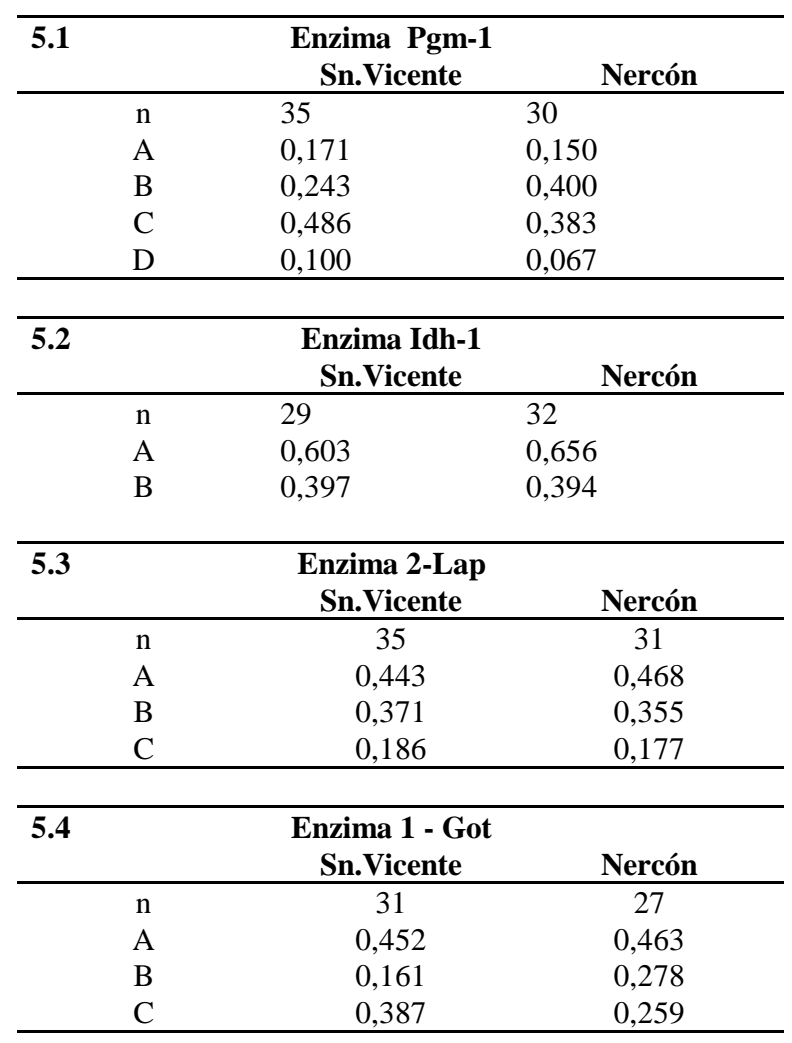

Estudios llevados a cabo por Riisgard et al. (1985), relacionados con la bioacumulación, eliminación y especiación química de mercurio en el bivalvo Macoma balthica, colectada en el Mar del Norte, próximo a la industria Cheminova, la cual produjo fungicidas que contenían mercurio entre los años 1956-1962. Las aguas de desechos de esta industria fueron accidentalmente liberadas al menos en dos ocasiones al ambiente acuático. Los autores establecieron bajas tasas de eliminación de mercurio y concluyeron que la mayor parte del elemento era inmovilizado en los tejidos.

Debido a afinidades genéticas, Macoma balthica ha sido habitualmente utilizada como especie monitora de mercurio en el ambiente marino, especialmente en aguas crónicamente contaminadas con el elemento.

En base a los resultados obtenidos en este trabajo, es posible deducir que por sus características genéticas, T. dombeii constituye una especie factible de ser ocupada como bioindicadora de contaminación crónica por mercurio, en las zonas costeras de Chile donde se encuentra presente esta especie. 


\subsection{Influencia de parámetros ambientales}

\subsubsection{Agua de mar}

La Tabla 6, muestra los resultados obtenidos relacionados con la concentración promedio de $\mathrm{Hg}$ total en el agua de mar recolectada de las estaciones $\mathrm{E}$ y A.

\section{Tabla 6}

Concentración de $\mathrm{Hg}$ total en agua de mar.

Concentration of total $\mathrm{Hg}$ in seawater.

\begin{tabular}{|c|c|c|c|c|}
\hline \multicolumn{2}{|c|}{ Estación } & \multirow{2}{*}{$\frac{\mathbf{n}}{2}$} & \multirow{2}{*}{$\begin{array}{c}\begin{array}{l}\text { X Hg Total } \\
\mu \text { Hg L }^{-1}\end{array} \\
0.60\end{array}$} & \multirow{2}{*}{$\begin{array}{l}\text { Rango } \\
0.10-1.10\end{array}$} \\
\hline E1 & suberficie & & & \\
\hline & fondo & 3 & 0,49 & $0.07-1,00$ \\
\hline \multirow[t]{2}{*}{ E2 } & superficie & 4 & 0,44 & $0.02-1,00$ \\
\hline & fondo & 4 & 0,38 & $0.01-0,90$ \\
\hline \multirow[t]{2}{*}{ E3 } & superficie & 4 & 0,75 & $0.01-2,50$ \\
\hline & fondo & 4 & 0,41 & $0,03-1,00$ \\
\hline \multirow[t]{2}{*}{ E4 } & superficie & 4 & 0,52 & $0,01-1,75$ \\
\hline & fondo & 4 & 0,36 & $0,06-0,90$ \\
\hline \multirow[t]{2}{*}{ A1 } & superficie & 4 & 0,83 & $0,15-2,50$ \\
\hline & fondo & 4 & 0,50 & $0,02-1,75$ \\
\hline \multirow[t]{2}{*}{ A2 } & superficie & 4 & 1,32 & $0,10-4,75$ \\
\hline & fondo & 4 & 0,35 & $0,01-1,25$ \\
\hline \multirow[t]{2}{*}{ A3 } & superficie & 4 & 0,67 & $0,22-1,60$ \\
\hline & fondo & 3 & 0,61 & $0,25-1,25$ \\
\hline \multirow[t]{2}{*}{ A4 } & superficie & 4 & 0,54 & $0,04-1,10$ \\
\hline & fondo & 4 & 0,41 & $0,01-1,00$ \\
\hline \multirow[t]{2}{*}{ A5 } & superficie & 3 & 0,56 & $0,17-1,10$ \\
\hline & fondo & 3 & 0,42 & $0,01-1,00$ \\
\hline \multirow[t]{2}{*}{ A6 } & superficie & 3 & 1,21 & $0,30-3,00$ \\
\hline & fondo & 3 & 0,53 & $0,20-1,10$ \\
\hline
\end{tabular}

De la Tabla 6, se puede apreciar que las concentraciones más altas de $\mathrm{Hg}$ total, se registraron en las muestras obtenidas de las estaciones $\mathrm{A}$, las que como presenta la Fig. 1, se encuentran ubicadas en las proximidades del efluente químico. El análisis de varianza practicado a los datos obtenidos en los dos grupos de estaciones, reveló que las diferencias encontradas son significativas ( $p>0.01)$.

Estos resultados permiten deducir el impacto negativo que ejerce dicho efluente en el ambiente acuático de $T$. dombeii, favoreciendo los procesos de acumulación de Hg en el organismo. Este hecho se ve reforzado al observar en la Tabla 6, que las muestras de agua superficial manifestaron contener concentraciones más altas de $\mathrm{Hg}$ total respecto de las muestras de agua de fondo, especialmente las recolectadas en las estaciones A1, A2 y A6. Las dos primeras se encuentran ubicadas en el punto más próximo al efluente químico (Fig. 1), y debido a que las descargas de residuos líquidos son constantes, el aporte de $\mathrm{Hg}$ al medio marino en estos puntos, es alto y sostenido. Es necesario hacer notar además, que el elevado nivel de $\mathrm{Hg}$ registrado en estas estaciones, se explica por la influencia de la corriente superficial, la que como se comentó anteriormente se dirige hacia el norte y en forma paralela a la línea costera de bahía San Vicente (Ahumada et al. 1989).

Estos resultados están de acuerdo con numerosos estudios similares a este, en los que igualmente se concluye que las diferencias en la concentración de $\mathrm{Hg}$ total en el ambiente acuático, depende de la proximidad o lejanía con que se ubican las estaciones de muestreo, respecto de la posición de la(s) fuente(s) que abastecen el elemento (Campbell et al. 1986, Santoro \& Koepp 1986, Shaw et al. 1988 y González 1991).

\subsubsection{Sólidos suspendidos}

La Tabla 7, presenta los resultados de las concentraciones promedio de $\mathrm{Hg}$ total en el material sólido suspendido recolectado en las estaciones A y E. De la Tabla 7, se puede apreciar que de la misma manera que para el caso del agua de mar, la concentración media de Hg total en el material sólido suspendido es significativamente mayor en las muestras obtenidas en las estaciones $\mathrm{A}$ que en las estaciones $\mathrm{E}$ ( $>0.01$ ), especialmente en aquellas muestras obtenidas de las estaciones más próximas al efluente (A1, A2, A4, E1 y E2, Fig. 1). Las cuatro primeras estaciones indicadas, se ubican frente al emisario y están además influenciadas por la dirección de la corriente superficial, todo lo cual justifica los resultados obtenidos.

Tabla 7

Concentración promedio de Hg Total en sólidos suspendidos.

Average concentration of total Hg in suspended particulate matter.

\begin{tabular}{llccc}
\hline & Estación & n & $\begin{array}{c}\bar{X} \text { Hg Total } \\
\text { Mg Hg L }\end{array}$ & Rango \\
\hline E1 & superficie & 2 & 10.05 & $7,96-12,14$ \\
& fondo & 2 & 12,79 & $12,71-12,87$ \\
E2 & superficie & 3 & 18,36 & $7,76-39,73$ \\
& fondo & 2 & 8,83 & $6,62-11,05$ \\
E3 & superficie & 3 & 7,64 & $4,37-10,16$ \\
& fondo & 2 & 12,57 & $5,39-19,75$ \\
E4 & superficie & 3 & 6,63 & $5,18-9,26$ \\
& fondo & 2 & 7,56 & $6,02-9,10$ \\
A1 & superficie & 2 & 62,27 & $46,90-77,64$ \\
& fondo & 3 & 32.78 & $14,31-42,69$ \\
A2 & superficie & 3 & 53,22 & $20,53-73,68$ \\
& fondo & 3 & 23,60 & $8,74-35,86$ \\
A3 & superficie & 2 & 7,78 & $6,10-9,47$ \\
& fondo & 3 & 27,53 & $4,86-61,00$ \\
A4 & superficie & 2 & 14,20 & $12,58-15,83$ \\
& fondo & 2 & 55,17 & $43,06-67,28$ \\
A5 & superficie & 2 & 42,99 & $4,50-81,48$ \\
& fondo & 2 & 8,49 & $4,56-12,43$ \\
A6 & superficie & 2 & 10,57 & $9,81-11,33$ \\
& fondo & 2 & 10,65 & $8,87-12,43$ \\
\hline
\end{tabular}


Vol. 36, No 1, 2001

No se encontraron diferencias significativas $(\mathrm{p}=$ 0.77 ) en las concentraciones de $\mathrm{Hg}$ total entre las muestras colectadas en la superficie $(n=24)$ respecto del fondo $(n=23)$. Estos resultados permiten deducir por una parte, el impacto negativo que ejerce el efluente químico en el ambiente de T. dombeii y por otra, el efecto que el material sólido suspendido pueda ejercer en la capacidad de bioacumulación de Hg, debido a que como se estableció anteriormente, este material constituye la base de la alimentación de estos organismos (Montecinos 1986).

Los resultados obtenidos en este estudio están de acuerdo con trabajos similares, los cuales igualmente concluyen que el $\mathrm{Hg}$ eliminado en zonas próximas a puntos de descarga de efluentes industriales, tiene como principal destino el material sólido suspendido en la columna de agua (Campbell et al.1986, Santoro \& Koepp 1986, Riisgard \& Hansen 1990, Grosheva 1993 y Díaz et al. 1995).

\subsubsection{Sedimento}

La Tabla 8, presenta las concentraciones promedio de $\mathrm{Hg}$ total y $\mathrm{CH}_{3} \mathrm{Hg}$ en cuatro muestras compuestas de sedimento superficial, recolectadas en cada estación E, durante todo el período de estudio.

De la Tabla 8, se puede observar que las concentraciones medias más altas de $\mathrm{Hg}$ total, se midieron en las muestras colectadas en las estaciones E3 y E4, no resultando significativas las diferencias. Estas estaciones se ubican en puntos más distantes respecto de la posición del efluente químico de la planta de clorosoda, y en las proximidades a la desembocadura del Estero Lenga (Fig. 1).

Esta situación justifica los resultados obtenidos, cuyos fundamentos son los mismos a los comentados para explicar las concentraciones de $\mathrm{Hg}$ total y $\mathrm{CH}_{3} \mathrm{Hg}$ en el hepatopáncreas y músculo pedal de $T$. dombeii (Tabla 2), lo que permite demostrar la influencia que ejercen los parámetros ambientales, en la capacidad de estos organismos para bioacumular ambos agentes químicos.

\section{Tabla 8}

Concentración de $\mathrm{Hg}$ Total y $\mathrm{CH}_{3} \mathrm{Hg}$ en sedimento superficial.

Concentration of total $\mathrm{Hg}$ and $\mathrm{CH}_{3} \mathrm{Hg}$ in surface sediment.

\begin{tabular}{|c|c|c|}
\hline Estación & $\begin{array}{l}\bar{X} \text { Hg Total } \\
\left(\mu g^{-1}, \text { base seca) }\right.\end{array}$ & $\begin{array}{l}\overline{\mathrm{X}} \mathrm{CH}_{3} \mathrm{Hg} \\
\left(\mu \mathrm{gg}^{-1}, \text { base seca) }\right.\end{array}$ \\
\hline E1 & $0,46 \pm 0,21$ & $0,25 \pm 0,02$ \\
\hline E2 & $0,37 \pm 0.18$ & $0,30 \pm 0,19$ \\
\hline E3 & $0,95 \pm 1,33$ & $0,22 \pm 0,12$ \\
\hline
\end{tabular}
E4
$0,73 \pm 0,66$
$0,19 \pm 0,08$

Respecto de los niveles de $\mathrm{CH}_{3} \mathrm{Hg}$, de la misma manera que para el caso de la concentración de Hg total, no muestran diferencias significativas entre estaciones de muestreo, revelando un grado de metilación constante con las muestras obtenidas de todas las estaciones y durante todo el período de muestreo.

El sedimento constituye la matriz ambiental donde se produce la metilación de $\mathrm{Hg}$ por acción bacteriana, transformación que depende tanto del contenido de materia orgánica como del tamaño de las partículas que lo compone (Breteler et al. 1981, IPCS 1989, Grosheva 1993 y Díaz et al. 1995).

Debido a que $T$. dombeii interactúa estrechamente con el sedimento, las altas concentraciones tanto de $\mathrm{Hg}$ total como de $\mathrm{CH}_{3} \mathrm{Hg}$ medidas en esta matriz, representan un impacto negativo para el organismo, lo que se manifiesta en la mayor bioacumulación de ambos contaminantes químicos tanto en el hepatopáncreas, como en el músculo pedal, precisamente en los organismos recolectados en las estaciones E3 y E4 (Tabla 3).

\subsubsection{Residuos industriales líquidos (RILes)}

La Tabla 9, muestra los resultados de las concentraciones promedio de $\mathrm{Hg}$ total medidas en dos puntos del efluente de la Planta de cloro-soda, perteneciente a la industria Occidental Chemical Chile S.A.I..

De la Tabla 9, se puede apreciar los altos niveles de $\mathrm{Hg}$ total en el efluente, siendo estos superiores en el punto más próximo a la Planta, respecto a aquel adyacente a la zona costera donde es vertido. Este hecho se puede explicar porque a medida que los residuos líquidos se desplazan hacia la zona costera, el $\mathrm{Hg}$ contenido en estos se va depositando en el material particulado, reduciéndose de esta manera el mercurio suspendido en él liquido.

Tabla 9

Concentración de Hg Total en RIL

Concentration of total $\mathrm{Hg}$ in industrial effluent

\begin{tabular}{lcc}
\hline Lugar de muestreo & n & $\begin{array}{l}\overline{\mathbf{X}} \text { Hg Total } \\
\boldsymbol{\mu g} \mathbf{H g ~ L}^{-1}\end{array}$ \\
\hline Proximidad a la Planta Química & 4 & $4,35 \pm 2,44$ \\
Próximo a la Zona Costera & 4 & $2,50 \pm 0,85$ \\
\hline
\end{tabular}

A partir de estos resultados, es posible atribuir una significativa influencia al citado efluente, respecto a uno de los principales aportes de $\mathrm{Hg}$ en el ambiente costero de bahía San Vicente, situación que se ha mantenido por espacio de $c a .30$ años. Los efectos en el ambiente 
marino, se manifiestan de manera más evidente hacia el norte del punto en que se vacían los desechos, debido a las condiciones hidrodinámicas que imperan en la zona costera de la bahía. Los principales efectos negativos evidenciados en este estudio son: una notoria disminución de la población de T. dombeii en la zona adyacente al efluente (estación El) y una marcada alta concentración de $\mathrm{Hg}$ total en el agua y material particulado en el área más próxima al emisario (estaciones Al, A2, A4, El y E2).

Sin embargo y en gran medida debido a los resultados obtenidos en este trabajo, la citada industria de cloro-soda ha reemplazado el proceso convencional de industrialización mediante el uso de electrodos de Hg, por el sistema de membranas, decisión adoptada posteriormente a la entrega de estos resultados.

Finalmente, los resultados obtenidos en este trabajo, coinciden con los logrados en otros estudios similares, en los cuales ha quedado de manifiesto la vinculación existente entre la presencia de efluentes procedentes de industrias procesadoras de cloro-álcali y altos niveles de exposición ambiental al Hg (IPCS 1989, González 1991 y Dangwal 1993).

\section{Conclusiones}

De los resultados obtenidos en este estudio, se puede concluir que:

La bioacumulación de $\mathrm{Hg}$ total y $\mathrm{CH}_{3} \mathrm{Hg}$ en algunos tejidos de T. dombeii, está influenciada por parámetros estacionales, espaciales y ambientales.

Tagelus dombeii, por su capacidad para bioacumular $\mathrm{Hg}$ y $\mathrm{CH}_{3} \mathrm{Hg}$ en sus tejidos y su homogeneidad genética a pesar de su amplia distribución geográfica, representa una especie adecuada para ser utilizada como indicadora de contaminación por $\mathrm{Hg}$ y $\mathrm{CH}_{3} \mathrm{Hg}$, en programas de monitoreo de la calidad ambiental de zonas costeras.

\section{Agradecimientos}

Este trabajo fue realizado en el Centro Universitario Internacional Europa-Latinoamérica para la Investigación y la Formación en Ciencias Ambientales (Centro EULA-Chile), Universidad de Concepción, Concepción-Chile y se contó con el aporte del Instituto de Cooperación Universitaria, Roma-Italia.

\section{Literatura Citada}

Ahumada R. 1994. Nivel de concentración e índice de bioacumulación para metales pesados $(\mathrm{Cd}, \mathrm{Cr}, \mathrm{Cu}, \mathrm{Hg}, \mathrm{Ni}$, $\mathrm{Pb}$ and $\mathrm{Zn}$ ) en tejido de invertebrados bénticos de bahía San Vicente, Chile. Revista de Biología Marina y Oceanografía, 29(1): 77 - 87.
Ahumada R, A Rudolph, S Madariaga \& F Carrasco. 1989. Descripción de las características oceanográficas de la bahía San Vicente y antecedentes sobre los efectos de la contaminación. Biología Pesquera, 18: 47- 52.

Borchardt T, S Burchert, H Hablizel, L Karbe \& $\mathbf{R}$ Zeitner. 1988. Trace metal concentration in mussels: Comparison between estuarine, coastal and offshore regions in the southeastern North Sea from 1983 to 1986. Marine Ecology, 42 (1):17 - 31.

Breteler RJ, JM Teal \& 1 Valiela. 1981. Retention and fate of experimentally added mercury in a Massachussetts salt marsh treated with sewage sludge. Marine Environmental Research, 5: 211 -225.

Bryan GW. 1973. The occurrence and seasonal variation of trace metals in the scallops Pecten maximum and Chíamys opercularis. Journal Marine Biology Assesment. U.K., 53: 145 - 166.

Campbell JA, EYL Chan \& JP Riley. 1986. The distribution of mercury in the Mersey Estuary. Marine Pollution Bulletin, 17 (1): 36 - 40.

Capelli R, R de Pellegrini, V Minganti \& E Amato. 1989. Preliminary results on the study and determination of total and organic mercury in marine organisms sampled during the scientific campaign 1987/1988. Annali di Chimica, 79: 561 - 569.

Castagna A, F Sinatra, G Castagna, A Stoli \& S Zafarana. 1985. Trace element evaluations in marine organisms. Marine Pollution Bulletin, 16 (10): 416-419.

Colina M. \& R Romero. 1989. Alternative mineralization procedures for total mercury determination in biological materials by cold vapour atomic absorption spectrometry. Atomic Absorption Spectroscopy, 10 (5): 160 - 164.

Chuecas L, L Balavanoff, M Silva \& R Zemelman. 1988. Programa de vigilancia de contaminantes en la bahía de Concepción VIII Región de Chile. En: CPPS-PNUMA. Versiones reducidas de contribuciones nacionales sobre niveles y distribución de metales pesados y pesticidas en agua, organismos y sedimentos marinos del Pacífico Sudeste. Plan de acción para la protección del medio ambiente y áreas costeras del Pacífico Sudeste: Colombia, Chile, Ecuador, Panamá y Perú. Bogotá, Colombia: 1 - 18.

Chuecas L. 1989. Contaminación por metales pesados en el litoral de la región del Bio-Bio, Concepción, Chile: el caso del mercurio y el cadmio. Ambiente y Desarrollo, 5 (1): 137-145.

Dangwal SK. 1993. Evaluation and control of mercury vapor exposure in the cell house of chlor -alkali Plant. Environmental Research, 60: 254 - 258.

Defeo O, A Masello \& C Layerle. 1988. Consideraciones metodológicas para el estudio del crecimiento en moluscos bivalvos. Informe UNESCO, Ciencias del Mar, 47:135 148. 
Díaz O. 1993. Tagelus dombeii como organismo indicador de la calidad del agua marina en la zona costera de la bahía San Vicente (VIII Región, Chile) y del riesgo de contaminación por mercurio y metilmercurio de origen antrópico. Tesis para optar al grado de Doctor en Ciencias Ambientales. Centro EULA Chile. Universidad de Concepción, Concepción, Chile.

Díaz O, R Frache, L Chuecas \& F Encina. 1995. Concentración de mercurio total en residuos industriales líquidos y su impacto en el área marina costera de bahía San Vicente. Contribuciones Científicas y Tecnológicas, Área de Ciencias Básicas, 110: 21 - 33.

Díaz O, L Chuecas \& E Recabarren. 1996. Biotransformation of mercury in marine sediments. International Colloquium on Process Related Analytical Chemistry in Environmental Investigations. Abstracts. Gramado, Brazil.

Donazzolo R, A Orio, B Pavoni \& O Perin. 1984. Heavy metals in sediments of the Venice Lagoon. Oceanology Acta, (1): 25 - 32.

Encina F, L Chuecas \& O Díaz. 1995. Metodología analítica base para la determinación de metales pesados en macroalgas. En: K. Alveal, M.E. Ferrario, E. C. Oliveira \& E. Sar (eds). Manual de métodos ficológicos. Universidad de Concepción, Concepción, Chile.

González H. 1991. Mercury pollution caused by chlor-álkali Plant. Water, Air and Soil Pollution, 56: 86-93.

González H \& L Brugmann. 1991. Heavy metals in litoral deposits off Havana City, Cuba. Chemistry and Ecology, 5: 171 - 179.

Grosheva E. 1993. Mercury transport, transformation and bioaccumulation in the ecosystem of mercury stibium geochemical province. Water, Air and Soil Pollution, 66: $381-388$.

Higth S. 1987. Rapid determination of methylmercury in fish and shellfish: collaborative study. Journal Association Official Analytical Chemistry, 70 (4): 667-672.

Hight S \& M Corcoran. 1987. Rapid determination of methylmercury in fish and shellfish. Method development. Journal Association Official Analytical Chemistry, 70 (1): 24 - 30 .

Hoffmann W. 1978. Distribución del mercurio como contaminante en el agua, sedimentos y organismos del Estero Lenga y áreas adyacentes en la bahía San Vicente (Concepción, Chile). Tesis para optar al título de Biólogo Marino. Universidad de Concepción, Concepción, Chile.

Horvat M, AR Byrne \& K May. 1990. A modified method for the determination of methylmercury by gas chromatography. Talanta, 37 (2): 207 - 212.

International Programme on Chemical Safety (IPCS). 1989. Environmental Health. Criteria 86. Mercury. Environmental Aspects. World Health Organization (WHO), United Nations (UN).
Kayrallah NH. 1985. The tolerance of Bathyporeia pilosa Lindstrom (Amphipoda: Haustoriidae) to organic and inorganic salts of mercury. Marine Environmental Research, 15: 137-151.

Leary RF \& HE Booke. 1989. Methods for fish biology. Chapter 5: Starch gel electrophoresis and species distinctions. C.B. Schreck \& P. B. Moyle (eds).

Lobban CS, PJ Harrison \& MJ Duncan. 1985. The Physiologycal Ecology of Seaweeds. Cambridge University Press. London.

Mechan BW, JT Carlton \& R Wenne. 1989. Genetic affinities of the Macoma balthica from the Pacific coast of North America: Evidence for recent introduction and historical distribution. Marine Biology, 102: 235 - 241.

Minganti V, $\mathbf{R}$ Capellí \& $\mathbf{R}$ de Pellegrini. 1990. The presence of inorganic and organic mercury and selenium in Nephrops norvegicus from the Ligurian Sea. The Science of Total Environment, 95: 53 - 60.

Montecinos J. 1986. Cuantificación de un banco de navajuelas (Tagelus dombeii) (Lamarck, 1818) en la bahía de Concepción (Chile), por el método ecoacústica. Tesis para optar al Título de Técnico Marino. Pontificia Universidad Católica de Chile, Sede Regional Talcahuano, Talcahuano, Chile.

Phillips DJ. 1980. Quantitative aquatic biological indicators. Their use to monitor trace metal and organochlorine pollution. Applied Science Publishers Ltd. Ripple Road, Barking, Essex, England.

Phillips DJ. 1990. Use of macroalgae and invertebrates as monitors of metals level in estuaries and coastal waters. In R. Furness \& P.S. Rainbow (eds). Heavy metals in the marine environment. C.R.S Press Inc.

Riisgard HU, T Kiorbe, F Mohlenberg, I Draback \& $\mathbf{P}$ Pheiffer Madsen. 1985. Accumulation, elimination and chemical speciation of mercury in the bivalves Mytilus edulis and Macoma balthica. Marine Biology, 86: 55-62.

Riisgard HU \& S Hansen. 1990. Biomagnification of mercury in a marine grazing food chain: algal cell Phaeodactylum tricornutum, mussels Mytilus edulis and flounders Platichthys flessus, studied by mean a stepwise reduction CVAA method. Marine Ecology Progress Series 62: $259-270$.

Rissanen K, J Erkama \& J K Miettinen. 1972. Experiments on microbiological methylation of mercury $(2+)$ ion by mud and sludge under aerobic and anaerobic conditions. In: M. Ruivo (ed.). Marine Pollution and Sea Life. Food and Agriculture Organization (FAO), United Nations.

Salamanca MA, L Chuecas \& F Carrasco. 1988. Heavy metal content and distribution in surface sediments from three areas of the chilean coast. Gayana (Miscelánea), 9 (1 - 4): 1 - 16. 
Santoro E \& S Koepp. 1986. Mercury levels in organisms in proximity to an old chemical site (Berrys Creek, Hackensack, Meadowlands), New Jersey (USA). Marine Pollution Bulletin, 17 (5): 219-224.

Sharp GJ, HS Samant \& OC Vaidya. 1988. Selected metal levels of commercially valuable seaweeds adjacent to and distant from point sources of contamination in Nova Scotia and New Brunswick. Bulletin Environmental Contamination Toxicology, 40: 724-730

Shaw BP, SB Sahu, SB Chaudhuri \& AK Panigrahi. 1988. Mercury in the Rushikulya River Estuary. Marine Pollution Bulletin, 19 (5): 233- 234.

The Royal Society. 1979. The Effects of Marine Pollution: Some Research Needs. A Memorandum: 5-78.

United Nations Environment Programme (UNEP). 1984. Sampling of selected marine organisms and sample preparation for trace metal analysis. Reference Methods for Marine Pollution Series, 7: 1- 19.
United Nations Environment Programme (UNEP). 1985. Determination of total mercury in marine sediments and suspended solids by cold vapour atomic absorption spectrophotometry. Reference Methods for Marine Pollution Studies, 26:1 - 7.

United Nations Environment Programme (UNEP). 1984. Determination of total mercury in selected marine organisms by cold vapour atomic absorption spectrophotometry, 1 - 11 .

Villarroel M \& J Stuardo. 1977. Observaciones sobre la morfología general, musculatura y aparato digestivo en Tagelus (Tagelus) dombeii y (T) Longisinuatus (Tellinacea: Solecurtidae). Malacología, 16 (2): 333 -352.

White SL \& S Rainbow. 1987. Heavy metals concentration and size effects in the mesopelagic decapod crustacean Systellaspis debilis. Marine Ecology, 37 (2) (3): 1 - 13. 